\section{Kidney \\ Blood Pressure Research}

\title{
Early Biomarkers of Renal Damage in Relation to Arterial Stiffness and In- flammation in Male Coronary Artery Disease Patients
}

\author{
Kaido Paapstel ${ }^{a, b} \quad$ Mihkel Zilmer $^{a, b} \quad J a a n$ Eha ${ }^{b, c} \quad K^{2}$ aspar Tootsi ${ }^{b} \quad$ Anneli Piir $^{a}$ \\ Jaak Kals ${ }^{\mathrm{a}, \mathrm{b}, \mathrm{d}}$ \\ ${ }^{a}$ Department of Biochemistry, Centre of Excellence for Translational Medicine; ${ }^{\mathrm{b}}$ Endothelial Centre; \\ 'Department of Cardiology; 'Department of Surgery, University of Tartu, Tartu, Estonia
}

\section{Key Words}

Atherosclerosis - Inflammation - Coronary artery disease - Arterial stiffness - Pulse wave velocity $•$ Novel kidney injury markers $\bullet$ L-FABP $・ \mathrm{KIM}-1 \cdot \mathrm{NGAL}$

\begin{abstract}
Background/Aims: Plasma neutrophil gelatinase-associated lipocalin (NGAL), urinary livertype fatty acid-binding protein (L-FABP) and urinary kidney injury molecule-1 (KIM-1) have emerged as promising biomarkers for both acute and chronic kidney injury that also provide prognostic value for cardiovascular morbidity and mortality. Our aim was to evaluate their relationships with arterial stiffness and inflammation in coronary artery disease (CAD) patients and in clinically healthy controls. Methods: We studied 52 patients with CAD (age $63.2 \pm 9.2$ years) and 41 healthy controls (age 60.1 \pm 7.2 years). Urinary L-FABP and KIM- 1 as well as serum NGAL, adiponectin and resistin levels were measured using the enzyme-linked immunosorbent assay method. The technique of applanation tonometry was used for non-invasive pulse wave analysis and pulse wave velocity assessments. Results: Urinary L-FABP and KIM-1 were independent determinants of cf-PWV for the CAD patients $\left(R^{2}=0.584, P<0.001\right)$ but not for the controls. Adiponectin correlated with log-KIM-1 $(r=0.31, \mathrm{P}=0.028)$ only for the patients, while NGAL correlated with WBC count $(r h o=0.29, \mathrm{P}=0.038 ; r=0.35, \mathrm{P}=0.029)$ and resistin ( $r h o=0.60$, $\mathrm{P}<0.001 ; \mathrm{r}=0.57, \mathrm{P}<0.001)$ for both the $\mathrm{CAD}$ and control groups, respectively. Conclusion: Our findings suggest that urinary L-FABP and KIM-1 may be independently associated with aortic stiffness in individuals with CAD.
\end{abstract}




\section{Kidney Blood Pressure Research}

Paapstel et al.: Early Biomarkers of Renal Damage and Arterial Stiffness

\section{Introduction}

Assessment of arterial stiffness provides useful information about the structural and functional alterations of the arterial tree. Stiffening of the aortic wall independently predicts all-cause and cardiovascular mortality in the general population, in chronic kidney disease (CKD) patients and in other high-risk groups [1-4]. Carotid-femoral pulse wave velocity (cfPWV) is considered the "gold standard" measurement of aortic stiffness and might be a clinically useful tool to identify patients with high cardiovascular risk [5-6].

Plasma neutrophil gelatinase-associated lipocalin (NGAL), urinary liver-type fatty acidbinding protein (L-FABP) and urinary kidney injury molecule-1 (KIM-1) have emerged as promising diagnostic and prognostic biomarkers for both acute and chronic kidney injury in different clinical settings [7-14]. Moreover, several studies have shown that these markers may also provide a prognostic value for cardiovascular morbidity and mortality. Plasma NGAL has been independently associated with cardiovascular disease and mortality in community-dwelling older adults [15]. Higher NGAL levels also predict mortality in patients with myocardial infarction as well as in heart failure patients with and without CKD [16, 17]. Urinary L-FABP is emerging as a useful marker for renal and cardiovascular prognosis in type 2 diabetes mellitus [18]. In acute coronary syndrome patients, elevated L-FABP levels may help identify individuals at high risk for future cardiovascular events [19]. Recent prospective community-based studies in elderly men have suggested that urinary KIM-1 is independently associated with cardiovascular mortality and incidence of heart failure [20, 21]. Thus, the above findings suggest that these proteins may also be useful predictors of the development of cardiovascular disease. However, little is known about the potential pathophysiological mechanisms underlying the relationship between these novel kidney biomarkers and cardiovascular risk.

Since renal and cardiovascular dysfunctions are intertwined, alterations in vascular structure and function may be at least partially responsible for early renal structural damage. In the current study, we hypothesized that increased arterial stiffness might be associated with elevated levels of early kidney damage biomarkers independently of traditional markers of renal function in coronary artery disease (CAD) patients with an estimated glomerular filtration rate (eGFR) of more than $60 \mathrm{~mL} / \mathrm{min} / 1.73 \mathrm{~m}^{2}$.

\section{Subjects and Methods}

\section{Study population}

Fifty-two male patients with angiographically proven CAD were prospectively studied. The patients were recruited from the Department of Cardiology, University of Tartu, Estonia. The exclusion criteria for the CAD group were any comorbid acute or chronic inflammatory disease, diabetes mellitus, myocardial infarction, cerebrovascular events or revascularization operation during the preceding 6 months, unstable angina, cardiac arrhythmias, clinically significant heart failure or valvular disease, reduced kidney function $\left(\mathrm{eGFR}<60 \mathrm{ml} / \mathrm{min} / 1.73 \mathrm{~m}^{2}\right)$, presence of cancer or endocrine pathology.

Forty-one age- and gender-matched apparently healthy controls were identified through local family physicians in the same geographical area. In the control group, the following exclusion criteria were applied: any comorbid acute or chronic inflammatory disease, CAD, cerebral or peripheral atherosclerotic disease, diabetes mellitus, cardiac arrhythmias, clinically significant heart failure or valvular disease, hypertension, reduced kidney function (eGFR $<60 \mathrm{ml} / \mathrm{min} / 1.73 \mathrm{~m}^{2}$ ), presence of cancer, infectious disease or endocrine pathology, or regular use of any medication.

\section{Study protocol}

All subjects completed a lifestyle and medical history questionnaire. Venous blood samples were drawn from each subject and spot morning urine specimens were collected from 45 patients and 37 controls. All samples were obtained between 8am and 11am after an overnight fast and abstinence from tobac- 


\section{Kidney Blood Pressure Research}

Paapstel et al.: Early Biomarkers of Renal Damage and Arterial Stiffness

co, alcohol, tea and coffee. Height and weight were assessed and body mass index (BMI) was calculated. The subjects were allowed to rest in a supine position in a quiet, temperature-controlled room for at least 10 minutes. Thereafter, brachial blood pressure and cf-PWV were assessed and pulse wave analysis was made. All hemodynamic measurements were taken in duplicate and averaged. The study protocol was approved by the Ethics Committee of the University of Tartu, and all subjects gave their written informed consent.

Arterial stiffness and central hemodynamics measurements

The cf-PWV was calculated from the pulse transit time using ECG-gated carotid and femoral artery waveform recordings over a known distance (SphygmoCor; AtCor Medical, Sydney, Australia) [22]. For calculation of cf-PWV, the distance from suprasternal notch over umbilicus to the femoral artery minus carotid arterial length was used. Central aortic waveforms and other hemodynamic parameters were evaluated non-invasively with the commercially available SphygmoCor device (AtCor Medical, Sydney, Australia) [22]. After 15 sequential high-quality radial waveforms were recorded at the patient's left wrist using arterial applanation tonometry, a validated generalized transfer function for calculation of the central aortic pressure waveform was used $[23,24]$.

\section{Biochemical analysis}

Venous blood samples were collected and centrifuged at room temperature. The serum was then pipetted into Eppendorf tubes and stored at $-70^{\circ} \mathrm{C}$ until analysis. Serum myeloperoxidase (MPO), adiponectin and NGAL levels were measured using an enzyme-linked immunosorbent assay (ELISA) (Myeloperoxidase enzyme immunoassay test kit, BIOCHECK, Inc. Foster City, CA; Human Total Adiponectin/Acrp30 immunoassay, R\&D Systems Europe, Abingdon, UK; Human Lipocalin-2/NGAL immunoassay, R\&D Systems Europe, Abingdon, UK, respectively). The levels of serum resistin, ferritin and interleukin-6 (IL-6) were determined using The Evidence Investigator (Metabolic Syndrome Array-1, Randox Laboratories, Crumlin, UK). Urine samples were collected into sterile plastic collection cups, aliquoted into Eppendorf tubes and kept frozen at $-70^{\circ} \mathrm{C}$ until analysis. The levels of urinary L-FABP and KIM-1 were measured using ELISA (Human Liver Fatty Acid Binding Protein-1 ELISA kit, BlueGene Biotech, Shanghai, China; HAVCR1 (Human), KIM-1, Abnova $\mathrm{GmbH}$, Heidelberg, Germany, respectively). The plasma levels of glucose, total cholesterol, low-density lipoprotein cholesterol (LDL-C), high-density lipoprotein cholesterol (HDL-C), triglycerides, white blood cell (WBC) count, high-sensitivity C-reactive protein (hs-CRP), serum creatinine, eGFR (calculated by the Chronic Kidney Disease Epidemiology Collaboration (CKD-EPI) equation [25]), cystatin C (CysC) and urinary creatinine were measured in the local clinical laboratory with automated analyzers using standard laboratory methods.

\section{Statistical analysis}

All statistical analyses were performed using the SPSS software for Windows, version 22.0. Dichotomous variables are expressed in percentages, whereas continuous variables are presented as mean and standard deviation or as median and interquartile range. The normality of the distribution of continuous variables was assessed using the Shapiro-Wilk test. The skewed distributions were normalized by logarithmic transformation. Comparisons between the two groups were performed by two-tailed Student's t-test and the Mann-Whitney U test, where appropriate. Univariate associations between predefined renal (L-FABP, KIM-1, NGAL, CysC, eGFR and creatinine), arterial stiffness (cf-PWV) and inflammatory parameters (WBC, IL-6, hs-CRP, resistin, adiponectin, MPO and ferritin) were analyzed using Pearson's r or Spearman's rho correlation, and multivariate analysis was applied to investigate the independent determinants of cfPWV. The variables entered into the model were drawn from univariate analyses and from relevant published observations (mean age, BMI, MAP, L-FABP, KIM-1, NGAL, eGFR, hs-CRP, IL-6, glucose, cholesterol, triglycerides, smoking status, antihypertensive therapy and statin use). Multivariate analyses were performed using a stepwise (forward followed by backward) multiple linear regression. Statistical significance was defined as $\mathrm{P}<0.05$. A Fisher's exact test or chi-square test was used to compare differences in the proportions between the two groups. All statistical tests were checked for violations of assumptions. 


\section{Kidney Blood Pressure Research}

Results

Characteristics of the study population

The clinical and laboratory characteristics of the CAD cases and the controls are presented in Table 1. There were no significant differences between the groups with respect to mean age, peripheral diastolic and central systolic or diastolic blood pressure, mean arterial pressure, current smoking status, total cholesterol, HDL-C, LDL-C, triglycerides, glucose, hs-CRP or ferritin levels. The two groups differed in BMI, height, peripheral systolic blood pressure, heart rate, cf-PWV, heart rate-corrected augmentation index (AIx@75), medication use, as well as in WBC count and serum MPO, IL-6, adiponectin and resistin levels. There were no significant differences in eGFR, serum creatinine, urea, CysC, NGAL, urinary L-FABP or KIM-1 levels between the patients and the controls.

Association between arterial stiffness and markers of renal function and tubular damage In a univariate analysis for the predefined variables, $\log$ - $\mathrm{L}-\mathrm{FABP}(\mathrm{r}=0.44, \mathrm{P}=0.002$; Figure 1), CysC $(\mathrm{r}=0.52, \mathrm{P}<0.001)$, eGFR (rho=-0.36, $\mathrm{P}=0.012)$ and creatinine $(\mathrm{r}=0.33, \mathrm{P}=0.021)$
Table 1. Clinical and laboratory characteristics of the study groups

\begin{tabular}{|c|c|c|c|}
\hline Variable & $\begin{array}{c}\text { CAD patients } \\
(n=52)\end{array}$ & $\begin{array}{c}\text { Controls } \\
(n=41)\end{array}$ & P-value \\
\hline Age (years) & $63.2 \pm 9.2$ & $60.1 \pm 7.2$ & 0.075 \\
\hline Body mass index $\left(\mathrm{kg} / \mathrm{m}^{2}\right)$ & $27.9 \pm 3.5$ & $26.0 \pm 3.4$ & 0.012 \\
\hline Height (m) & $176.2 \pm 6.4$ & $179.3 \pm 6.5$ & 0.025 \\
\hline Peripheral SBP (mmHg) & $135.0 \pm 14.5$ & $128.4 \pm 13.2$ & 0.027 \\
\hline Peripheral DBP (mmHg) & $78.5 \pm 8.0$ & $77.9 \pm 7.3$ & 0.706 \\
\hline Central SBP (mmHg) & $122.7 \pm 11.1$ & $119.8 \pm 15.1$ & 0.303 \\
\hline Central DBP (mmHg) & $79.7 \pm 7.6$ & $78.4 \pm 6.7$ & 0.378 \\
\hline MAP (mmHg) & $96.0(91.6-101.4)$ & $92.5(89.5-99.5)$ & 0.103 \\
\hline Heart rate (bpm) & $62.8 \pm 8.3$ & $57.8 \pm 7.1$ & 0.003 \\
\hline WBC count $\left(\times 10^{9} / \mathrm{L}\right)$ & $6.4(5.2-7.9)$ & $5.1(4.7-5.8)$ & 0.001 \\
\hline Total cholesterol $(\mathrm{mmol} / \mathrm{l})$ & $5.1 \pm 1.0$ & $5.5 \pm 0.9$ & 0.080 \\
\hline HDL-cholesterol (mmol/l) & $1.5 \pm 0.4$ & $1.6 \pm 0.4$ & 0.153 \\
\hline LDL-cholesterol $(\mathrm{mmol} / \mathrm{l})$ & $3.2(2.8-4.1)$ & $3.7(3.3-4.3)$ & 0.058 \\
\hline Triglycerides (mmol/l) & $1.2(0.8-1.6)$ & $1.0(0.7-1.4)$ & 0.311 \\
\hline Glucose $(\mathrm{mmol} / \mathrm{l})$ & $5.8(5.3-6.3)$ & $5.8(5.4-6.1)$ & 0.858 \\
\hline hs-CRP (mg/l) & $1.3(0.7-2.8)$ & $1.2(0.7-2.1)$ & 0.423 \\
\hline Myeloperoxidase (ng/mL) & $58.4(35.3-110.7)$ & $45.2(28.0-62.6)$ & 0.014 \\
\hline Interleukin-6 (pg/mL) & $1.33(0.74-1.98)$ & $0.95(0.64-1.29)$ & 0.048 \\
\hline Ferritin (ng/mL) & $128.0(68.6-202.0)$ & $92.7(54.7-190.7)$ & 0.110 \\
\hline Adiponectin (ng/mL) & $5701 \pm 2890$ & $7081 \pm 3612$ & 0.045 \\
\hline Resistin (ng/mL) & $3.4(2.6-4.5)$ & $2.8(2.4-3.5)$ & 0.043 \\
\hline AIx@75 (\%) & $18.9 \pm 7.2$ & $15.1 \pm 8.0$ & 0.021 \\
\hline $\mathrm{cf}-\mathrm{PWV}(\mathrm{m} / \mathrm{s})$ & $9.7 \pm 2.6$ & $8.2 \pm 1.7$ & 0.003 \\
\hline eGFR (ml/min $\left./ 1,73 \mathrm{~m}^{2}\right)$ & $85(73-97)$ & $89(79-93)$ & 0.847 \\
\hline S-Creat $(\mu \mathrm{mol} / \mathrm{L})$ & $83.2 \pm 12.3$ & $84.0 \pm 11.2$ & 0.750 \\
\hline S-Urea (mmol/L) & $5.7(4.7-7.0)$ & $5.3(4.5-6.0)$ & 0.114 \\
\hline Cystatin C (mg/L) & $0.93 \pm 0.14$ & $0.90 \pm 0.10$ & 0.278 \\
\hline NGAL (ng/mL) & $74.6(61.9-83.5)$ & $73.7(59.4-85.0)$ & 0.892 \\
\hline L-FABP/Creat (ng/mmol) & $169.0(121.9-228.2)$ & $187.2(136.5-271.3)$ & 0.244 \\
\hline KIM-1/Creat (ng/mmol) & $79.6(53.6-110.7)$ & $85.8(54.7-118.5)$ & 0.636 \\
\hline Current smoking, n (\%) & $13(25)$ & $5(12)$ & 0.214 \\
\hline \multicolumn{4}{|l|}{ Medication, $\mathrm{n}(\%)$} \\
\hline Antihypertensives & $48(92)$ & $0(0)$ & $<0.001$ \\
\hline Antiplatelets & $34(65)$ & $0(0)$ & $<0.001$ \\
\hline Statins & $28(54)$ & $0(0)$ & $<0.001$ \\
\hline
\end{tabular}

The values are expressed as means $( \pm$ standard deviation), medians (interquartile range), or prevalence (\%). CAD, coronary artery disease; SBP, systolic blood pressure; DBP, diastolic blood pressure; MAP, mean arterial pressure; WBC, white blood cell count; HDL, high-density lipoprotein; LDL, low-density lipoprotein; hs-CRP, highsensitivity C-reactive protein; AIx@75, augmentation index adjusted to a heart rate of 75 beats per minute; cf-PWV, carotid-femoral pulse wave velocity; eGFR, estimated glomerular filtration rate; Creat, creatinine; NGAL, neutrophil gelatinase-associated lipocalin; L-FABP, liver-type fatty acid-binding protein; KIM-1, kidney injury molecule-1. 


\section{Kidney Blood Pressure Research}

correlated positively with cf-PWV for the CAD group but not for the controls (data not shown). Also, log-KIM-1 showed a borderline significant relationship ( $r=0.29$, $\mathrm{P}=0.062$ ) with aortic stiffness for the patients. In multivariate analysis with cf-PWV as the dependent variable, L-FABP and KIM-1 were the only renal markers that remained significant after adjustment for potential confounders (mean age, BMI, MAP, NGAL, eGFR, hsCRP, IL-6, glucose, cholesterol, triglycerides, smoking status, antihypertensive therapy and statin use) (R2=0.58; $\mathrm{P}<0.001$; Table 2). In the post hoc subgroup analyses based on eGFR levels, $\mathrm{L}-\mathrm{FABP}(\mathrm{r}=0.6, \mathrm{P}=0.002)$ showed a strong and CysC $(\mathrm{r}=0.4, \mathrm{P}=0.043)$ a moderate correlation with cf-PWV for the subgroup of CAD patients with eGFR between 60 and $89 \mathrm{~mL} /$ $\min / 1.73 \mathrm{~m}^{2}$.

Serum NGAL was not correlated with cf-PWV or any other measure of arterial stiffness for either CAD patients or controls (data not shown).

In the control group, a significant inverse correlation was found between serum resistin levels and logL-FABP $\quad(r=-0.34, \quad \mathrm{P}=0.045)$. Serum NGAL levels correlated with WBC count (rho $=0.29$, $\mathrm{P}=0.038 ; \mathrm{r}=0.35, \mathrm{P}=0.029)$ and resistin (rho $=0.60, \mathrm{P}<0.001$; $r=0.57, P<0.001$ ) for the CAD and control groups, respectively, and with serum creatinine (rho=0.31, $\mathrm{P}=0.030$ ) only for the CAD group. Urinary log-

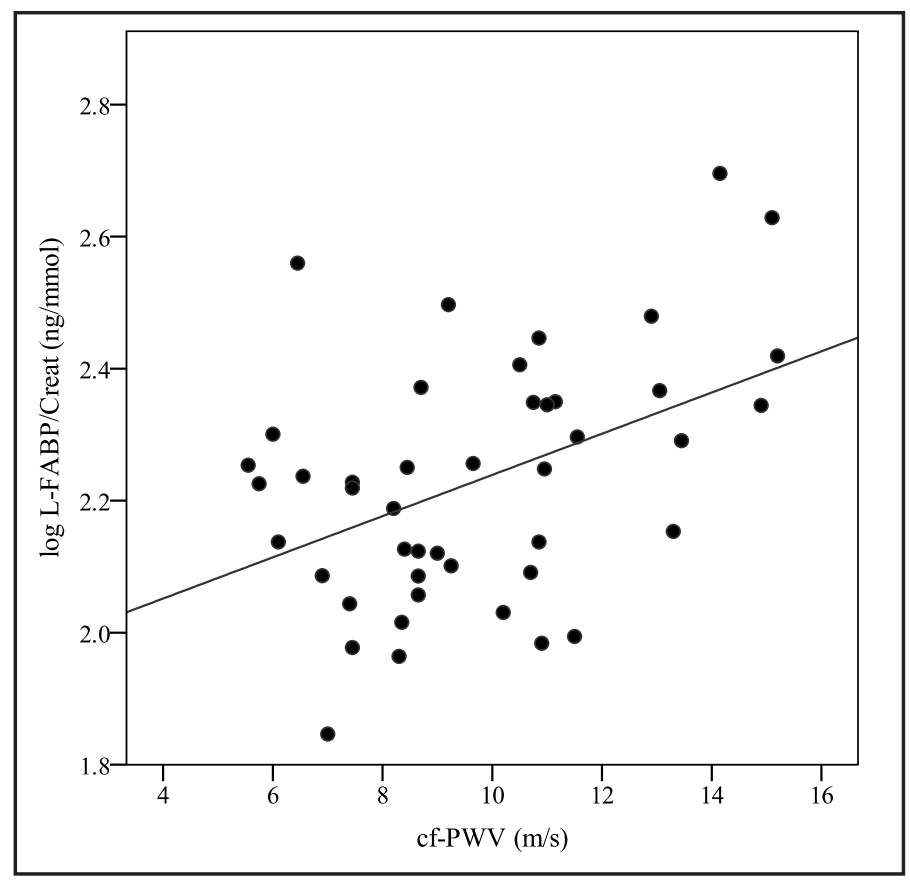

Fig. 1. Scatterplot showing linear correlation between carotid-femoral pulse wave velocity (cf-PWV) and logarithmically transformed urinary liver-type fatty acid-binding protein (log-L-FABP) for the coronary artery disease patients $(r=0.44, \mathrm{P}=0.002)$.

Table 2. Multiple regression model for the CAD group with cf-PWV as the dependent variable

\begin{tabular}{lccc}
\hline Variable & $\begin{array}{c}\text { Regression } \\
\text { coefficient }\end{array}$ & $\begin{array}{c}\text { Standard } \\
\text { error }\end{array}$ & $P$ value \\
\hline Mean age & 0.161 & 0.029 & $<0.001$ \\
L-FABP/Creat & 0.011 & 0.003 & 0.001 \\
Body mass index & 0.197 & 0.077 & 0.014 \\
KIM-1/Creat & 0.013 & 0.006 & 0.023 \\
\hline
\end{tabular}

$R^{2}=0.584, P<0.001$. Mean age, body mass index, mean arterial pressure, L-FABP/Creat, KIM-1/Creat, neutrophil gelatinaseassociated lipocalin, cystatin $\mathrm{C}$, estimated glomerular filtration rate, high-sensitivity C-reactive protein, interleukin-6, glucose, cholesterol, triglycerides, smoking status, antihypertensive therapy and statin use were entered as independent variables into the regression model. CAD, coronary artery disease; cf-PWV, carotid-femoral pulse wave velocity; L-FABP, liver-type fatty acid-binding protein; KIM-1, kidney injury molecule-1; Creat, creatinine.

KIM-1 was linearly correlated with serum creatinine ( $r=0.33, \mathrm{P}=0.019)$, adiponectin $(\mathrm{r}=0.31$, $\mathrm{P}=0.028)$ and $\log$-ferritin $(\mathrm{r}=-0.32, \mathrm{P}=0.022)$ levels for the CAD group while no such correlations were found for the controls. 


\section{Kidney Blood Pressure Research}

\section{Discussion}

In the present study, we demonstrated correlations between aortic stiffness and markers of both renal function and tubular damage in the symptomatic CAD patients. The novel findings that urinary L-FABP and KIM-1 are independently associated with cf-PWV in CAD (Table 2) extend our current knowledge of these proteins and may partially explain their value as biomarkers for cardiovascular prognosis in different study populations [18-21].

L-FABP is involved in the fatty acid uptake, intracellular transport and metabolism [26, 27]. In the case of kidney damage, the expression of L-FABP in the proximal tubular cells is upregulated [28-31] It has been previously shown that the estimated contribution of serum L-FABP to urinary L-FABP levels is only $3 \%$, hence the L-FABP that is found in urine is produced primarily by the tubular cells $[32,33]$. Interestingly, the mean urinary levels of this protein were moderately lower in the subjects with CAD compared to the controls in our study, however this difference was not statistically significant. Since L-FABP has been reported as a renoprotective endogenous antioxidant, it can be hypothesized that its lower levels may reflect reduced kidney protection in atherosclerotic patients without moderate to severe CKD [34-36].

In the presence of increased arterial stiffness, the kidneys are particularly susceptible to the damage resulting from high pulsatile pressure and flow [37]. We observed elevated values of cf-PWV and AIx@75 for the subjects with CAD. Furthermore, besides its independent association with L-FABP and KIM-1, cf-PWV was also correlated with serum creatinine, CysC and eGFR in these patients, but not in the healthy controls. Although the type of causality could not be determined, these findings support the view that increased arterial stiffness (and thus high pulsatile pressure and flow) contributes to renal dysfunction and propose that urinary L-FABP and KIM-1 may serve as novel biomarkers that reflect this relationship even in the early stages of renal damage. However, it should be noted that this relationship might be bidirectional and could also be affected by some other pathophysiological processes.

We acknowledge that eGFR tends to be less accurate at levels above $60 \mathrm{ml} / \mathrm{min}$ per $1.73 \mathrm{~m}^{2}$ [38]. However, the CKD-EPI creatinine equation used in the current work performs better than the Modification of Diet in Renal Disease Study formula, especially at higher GFR levels $[25,38]$. When we performed post hoc subgroup analyses based on eGFR levels $\mathrm{L}-\mathrm{FABP}$ showed a strong and CysC a moderate correlation with cf-PWV for the subgroup of CAD patients with eGFR between 60 and $89 \mathrm{~mL} / \mathrm{min} / 1.73 \mathrm{~m}^{2}$, whereas none of the measured kidney biomarkers retained as significant correlates of aortic stiffness for the patients with eGFR $\geq 90 \mathrm{~mL} / \mathrm{min} / 1.73 \mathrm{~m}^{2}$ (see the Results section). Although these findings are potentially interesting, larger studies with pre-specified subgroup analyses are warranted to explore these possible differences between CAD patients with eGFR $\geq 90 \mathrm{~mL} / \mathrm{min} / 1.73 \mathrm{~m}^{2}$ and those with eGFR between 60 and $89 \mathrm{~mL} / \mathrm{min} / 1.73 \mathrm{~m}^{2}$.

The lack of correlations between kidney biomarkers and cf-PWV in healthy subjects might be due to their better preserved vascular function and reduced inflammation compared to CAD patients. Indeed, decreased serum adiponectin, higher WBC count and elevated IL-6, MPO and resistin levels indicated systemic inflammation in the CAD group when juxtaposed with the healthy controls (Table 1). Previous findings suggest that elevated resistin may be especially undesirable in the case of reduced adiponectin levels [39, 40]. Although the true function of resistin still remains to be established, it seems to play significant regulatory roles in various biological processes including low-grade inflammation and atherosclerosis [41].

Urinary KIM-1 showed a borderline significant correlation with cf-PWV for the CAD patients. However, this relationship reached statistical significance after adjusting for potential confounders (Table 2). KIM-1 functions as a transmembrane phosphatidyl serine receptor that recognizes apoptotic cells and has also been suggested as an early marker for tubular damage $[42,43]$. A recent study in mice demonstrated that by facilitating the phagocytic 


\section{Kidney \\ Blood Pressure Research}

process, KIM-1 might have a protective anti-inflammatory role in the early stages of acute kidney injury [44]. In our work, urinary KIM-1 correlated positively with serum adiponectin and inversely with ferritin for the CAD patients but not for the controls. Although the association between KIM-1 and aortic stiffness in the CAD group was rather weak, it reveales a novel aspect of this prognostic biomarker and deserves further study.

Several correlations also emerged between serum NGAL and indices of kidney function and inflammation. Positive relationships with WBC count and resistin for both groups are in line with the view that serum NGAL could serve as an inflammatory marker in a range of clinical settings [45-47]. This lipocalin is expressed by neutrophils and various epithelial cells and has received attention as an acute kidney injury marker because of its early upregulation in the damaged tubular cells $[7,48]$. High expression of NGAL in atheromatous plaques and its role in inflammation might explain the previous finding that this biomarker could prove useful in discriminating between unstable and stable CAD patients [49,50]. However, serum NGAL was not related to arterial stiffness in the current study. Further investigations will evidently determine its true role in inflammation and vascular damage.

Several limitations should be noted. First, the number of subjects in our cross-sectional study was relatively small and, thus, larger samples of CAD patients without moderate to severe CKD are needed to confirm our results. In addition, prospective longitudinal studies are required in these patients to determine the contribution of changes in arterial stiffness to renal damage as well as to clarify the role of urinary L-FABP and KIM-1 as potential early reflectors of this pathophysiological interplay. Third, only male participants were recruited to avoid the possible confounding effects of estrogen. Hence our findings cannot be fully extrapolated to women. Fourth, urine albumin-to-creatinine ratio was not determined in the current study [51]. Also, we could not withdraw the CAD patients from their medications to exclude their potential effects on hemodynamic parameters and on levels of biochemical markers. Finally, long-term health consequences of smoking cannot be ruled out.

\section{Conclusion}

We found independent associations between urinary L-FABP, KIM-1 and aortic stiffness for the CAD patients with eGFR above $60 \mathrm{ml} / \mathrm{min}$ per $1.73 \mathrm{~m}^{2}$. Therefore, in these subjects, measurements of L-FABP and KIM-1 may help to further explore the interplay between early alterations in renal function and vascular damage.

\section{Disclosure Statement}

The authors declare no conflict of interest.

\section{Acknowledgments}

We are indebted to Ester Jaigma for the linguistic revision of the manuscript. We thank Mart Kals for guidance and help with statistical analysis. This study was supported by a grant of the Estonian Science Foundation (No. 9094), by Personal Research Funding (GMVBS1169P), by Institutional Research Funding (Nos. IUT20-42, IUT2-7) from the Estonian Ministry of Education and Research, and by the European Union through the European Regional Development Fund (Project No. 2014-2020.4.01.15-0012). 


\section{Kidney \\ Blood Pressure Research}

\section{References}

1 Mattace-Raso FU, van der Cammen TJ, Hofman A, van Popele NM, Bos ML, Schalekamp MA, Asmar R, Reneman RS, Hoeks AP, Breteler MM, Wit-teman JC: Arterial stiffness and risk of coronary heart disease and stroke: the Rotterdam Study. Circulation 2006;113:657-663.

2 Baumann M, Wassertheurer S, Suttmann Y, Burkhardt K, Heemann U: Aortic pulse wave velocity predicts mortality in chronic kidney disease stages 2-4. J Hypertens 2014;32:899-903.

3 Blacher J, Pannier B, Guerin AP, Marchais SJ, Safar ME, London GM: Carotid arterial stiffness as a predictor of cardiovascular and all-cause mortality in end-stage renal disease. Hypertension 1998;32:570-574.

4 Cruickshank K, Riste L, Anderson SG, Wright JS, Dunn G, Gosling RG: Aortic pulse-wave velocity and its relationship to mortality in diabetes and glucose intolerance: an integrated index of vascular function? Circulation 2002;106:2085-2090.

5 Laurent S, Cockcroft J, Van Bortel L, Boutouyrie P, Giannattasio C, Hayoz D, Pannier B, Vlachopoulos C, Wilkinson I, Struijker-Boudier H: Expert consensus document on arterial stiffness: methodological issues and clinical applications. Eur Heart J 2006;27:2588-2605.

6 Ben-Shlomo Y, Spears M, Boustred C, May M, Anderson SG, Benjamin EJ, Boutouyrie P, Cameron J, Chen CH, Cruickshank JK, Hwang SJ, Lakatta EG, Laurent S, Maldonado J, Mitchell GF, Najjar SS, Newman AB, Ohishi M, Pannier B, Pereira T, Vasan RS, Shokawa T, Sutton-Tyrell K, Verbeke F, Wang KL, Webb DJ, Willum Hansen T, Zoungas S, McEniery CM, Cockcroft JR, Wilkinson IB: Aortic pulse wave velocity improves cardiovascular event prediction: an individual participant meta-analysis of prospective observational data from 17,635 subjects. J Am Coll Cardiol 2014;63:636-646.

7 Haase M, Bellomo R, Devarajan P, Schlattmann P, Haase-Fielitz A, NGAL Meta-analysis Investigator Group: Accuracy of neutrophil gelatinase-associated lipocalin (NGAL) in diagnosis and prognosis in acute kidney injury: a systematic review and meta-analysis. Am J Kidney Dis 2009;54:1012-1024.

8 Bolignano D, Lacquaniti A, Coppolino G, Donato V, Campo S, Fazio MR, Nicocia G, Buemi M: Neutrophil gelatinase-associated lipocalin (NGAL) and progression of chronic kidney disease. Clin J Am Soc Nephrol 2009;4:337-344.

9 Kamijo A, Sugaya T, Hikawa A, Yamanouchi M, Hirata Y, Ishimitsu T, Numabe A, Takagi M, Hayakawa H, Tabei F, Sugimoto T, Mise N, Kimura K: Clinical evaluation of urinary excretion of liver-type fatty acidbinding protein as a marker for the monitoring of chronic kidney disease: a multicenter trial. J Lab Clin Med 2005;145:125-133.

10 Parr SK, Clark AJ, Bian A, Shintani AK, Wickersham NE, Ware LB, Ikizler TA, Siew ED: Urinary L-FABP predicts poor outcomes in critically ill patients with early acute kidney injury. Kidney Int 2015;87:640-648.

11 Xue W, Xie Y, Wang Q Xu W, Mou S, Ni Z: Diagnostic performance of urinary kidney injury molecule-1 and neutrophil gelatinase-associated lipocalin for acute kidney injury in an obstructive nephropathy patient. Nephrology (Carlton) 2014;19:186-194.

12 Peralta CA, Katz R, Bonventre JV, Sabbisetti V, Siscovick D, Sarnak M, Shlipak MG: Associations of urinary levels of kidney injury molecule 1 (KIM-1) and neutrophil gelatinase-associated lipocalin (NGAL) with kidney function decline in the Multi-Ethnic Study of Atherosclerosis (MESA). Am J Kidney Dis 2012;60:904911.

13 Arun O, Celik G, Oc B, Unlu A, Celik JB, Oc M, Duman A: Renal effects of coronary artery bypass graft surgery in diabetic and non-diabetic patients: a study with urinary neutrophil gelatinase-associated lipocalin and serum cystatin C. Kidney Blood Press Res 2015;40:141-152.

14 Helanova K, Spinar J, Parenica J: Diagnostic and prognostic utility of neutrophil gelatinase-associated lipocalin (NGAL) in patients with cardiovascular diseases--review. Kidney Blood Press Res 2014;39:623639.

15 Daniels LB, Barrett-Connor E, Clopton P, Laughlin GA, Ix JH, Maisel AS: Plasma neutrophil gelatinaseassociated lipocalin is independently associated with cardiovascular disease and mortality in communitydwelling older adults: The Rancho Bernardo Study. J Am Coll Cardiol 2012;59:1101-1109.

16 Lindberg S, Pedersen SH, Mogelvang R, Jensen JS, Flyvbjerg A, Galatius S, Magnusson NE: Prognostic utility of neutrophil gelatinase-associated lipocalin in predicting mortality and cardiovascular events in patients with ST-segment elevation myocardial infarction treated with primary percutaneous coronary intervention. J Am Coll Cardiol 2012;60:339-345. 


\section{Kidney \\ Blood Pressure Research}

Kidney Blood Press Res 2016;41:488-497

DOI: $10.1159 / 000443450$

Published online: July 20, 2016

(C) 2016 The Author(s). Published by S. Karger AG, Base www.karger.com/kbr

17 van Deursen VM1, Damman K, Voors AA, van der Wal MH, Jaarsma T, van Veldhuisen DJ, Hillege HL: Prognostic value of plasma neutrophil gelatinase-associated lipocalin for mortality in patients with heart failure. Circ Heart Fail 2014;7:35-42.

18 Araki S, Haneda M, Koya D, Sugaya T, Isshiki K, Kume S, Kashiwagi A, Uzu T, Maegawa H: Predictive effects of urinary liver-type fatty acid-binding protein for deteriorating renal function and incidence of cardiovascular disease in type 2 diabetic patients without advanced nephropathy. Diabetes Care 2013;36:1248-1253.

19 Matsumori R, Shimada K, Kiyanagi T, Hiki M, Fukao K, Hirose K, Ohsaka H, Miyazaki T, Kume A, Yamada A, Takagi A, Ohmura H, Miyauchi K, Daida H: Clinical significance of the measurements of urinary liver-type fatty acid binding protein levels in patients with acute coronary syndrome. J Cardiol 2012;60:168-173.

20 Carlsson AC, Larsson A, Helmersson-Karlqvist J, Lind L, Ingelsson E, Larsson TE, Bottai M, Sundström J, Ärnlöv J: Urinary kidney injury molecule-1 and the risk of cardiovascular mortality in elderly men. Clin J Am Soc Nephrol 2014;9:1393-1401.

21 Carlsson AC, Larsson A, Helmersson-Karlqvist J, Lind L, Ingelsson E, Larsson TE, Sundström J, Arnlöv J: Urinary kidney injury molecule 1 and incidence of heart failure in elderly men. Eur J Heart Fail 2013;15:441-446.

22 Wilkinson IB, Fuchs SA, Jansen IM, Spratt JC, Murray GD, Cockcroft JR, Webb DJ: Reproducibility of pulse wave velocity and augmentation index measured by pulse wave analysis. J Hypertens 1998;16:2079-2084.

23 Pauca AL, O'Rourke MF, Kon ND: Prospective evaluation of a method for estimating ascending aortic pressure from the radial artery pressure waveform. Hypertension 2001;38:932-937.

24 Adji A, O'Rourke MF, Namasivayam M: Arterial stiffness, its assessment, prognostic value, and implications for treatment. Am J Hypertens 2011;24:5-17.

25 Levey AS, Stevens LA, Schmid CH, Zhang YL, Castro AF $3^{\text {rd }}$, Feldman HI, Kusek JW, Eggers P, Van Lente F, Greene T, Coresh J; CKD-EPI (Chronic Kidney Disease Epidemiology Collaboration): A new equation to estimate glomerular filtration rate. Ann Intern Med 2009;150:604-612.

26 Murphy EJ, Prows DR, Jefferson JR, Schroeder F: Liver fatty acid-binding protein expression in transfected fibroblasts stimulates fatty acid uptake and metabolism. Biochim Biophys Acta 1996;1301:191-198.

27 Antonenkov VD, Sormunen RT, Ohlmeier S, Amery L, Fransen M, Mannaerts GP, Hiltunen JK: Localization of a portion of the liver isoform of fatty-acid-binding protein (L-FABP) to peroxisomes. Biochem J 2006;394:475-484.

28 Oyama Y, Takeda T, Hama H, Tanuma A, Iino N, Sato K, Kaseda R, Ma M, Yamamoto T, Fujii H, Kazama JJ, Odani S, Terada Y, Mizuta K, Gejyo F, Saito A: Evidence for megalin-mediated proximal tubular uptake of L-FABP, a carrier of potentially nephrotoxic molecules. Lab Invest 2005;85:522-531.

29 Ferguson MA, Vaidya VS, Waikar SS, Collings FB, Sunderland KE, Gioules CJ, Bonventre JV: Urinary livertype fatty acid-binding protein predicts adverse outcomes in acute kidney injury. Kidney Int 2010;77:708714.

30 Noiri E, Doi K, Negishi K, Tanaka T, Hamasaki Y, Fujita T, Portilla D, Sugaya T: Urinary fatty acid-binding protein 1: an early predictive biomarker of kidney injury. Am J Physiol Renal Physiol 2009;296:F669-F679.

31 Yamamoto T, Noiri E, Ono Y, Doi K, Negishi K, Kamijo A, Kimura K, Fujita T, Kinukawa T, Taniguchi H, Nakamura K, Goto M, Shinozaki N, Ohshima S, Sugaya T: Renal L-type fatty acid-binding protein in acute ischemic injury. J Am Soc Nephrol 2007;18:2894-2902.

32 Kamijo A, Sugaya T, Hikawa A, Yamanouchi M, Hirata Y, Ishimitsu T, Numabe A, Takagi M, Hayakawa H, Tabei F, Sugimoto T, Mise N, Omata M, Kimura K: Urinary liver-type fatty acid binding protein as a useful biomarker in chronic kidney disease. Mol Cell Biochem 2006;284:175-182.

33 Imai N, Yasuda T, Kamijo-Ikemori A, Shibagaki Y, Kimura K: Distinct roles of urinary liver-type fatty acidbinding protein in non-diabetic patients with anemia. PLoS One 2015;10:e0126990.

34 Matsui K, Kamijo-Ikemorif A, Sugaya T, Yasuda T, Kimura K: Renal liver-type fatty acid binding protein (L-FABP) attenuates acute kidney injury in aristolochic acid nephrotoxicity. Am J Pathol 2011;178:10211032.

35 Kanaguchi Y, Suzuki Y, Osaki K, Sugaya T, Horikoshi S, Tomino Y: Protective effects of L-type fatty acidbinding protein (L-FABP) in proximal tubular cells against glomerular injury in anti-GBM antibodymediated glomerulonephritis. Nephrol Dial Transplant 2011;26:3465-3473. 


\section{Kidney \\ Blood Pressure Research}

36 Mori Y, Sato N, Kobayashi Y, Ochiai R: Low levels of urinary liver-type fatty acid-binding protein may indicate a lack of kidney protection during aortic arch surgery requiring hypothermic circulatory arrest. J Clin Anesth 2014;26:118-124.

37 Mitchell GF: Effects of central arterial aging on the structure and function of the peripheral vasculature: implications for end-organ damage. J Appl Physiol 2008;105:1652-1660.

38 Stevens LA, Schmid CH, Greene T, Zhang YL, Beck GJ, Froissart M, Hamm LL, Lewis JB, Mauer M, Navis GJ, Steffes MW, Eggers PW, Coresh J, Levey AS: Comparative performance of the CKD Epidemiology Collaboration (CKD-EPI) and the Modification of Diet in Renal Disease (MDRD) Study equations for estimating GFR levels above $60 \mathrm{~mL} / \mathrm{min} / 1.73 \mathrm{~m}^{2}$. Am J Kidney Dis 2010;56:486-495.

39 Spoto B, Mattace-Raso F, Sijbrands E, Pizzini P, Cutrupi S, D'Arrigo G, Tripepi G, Zoccali C, Mallamaci F: Resistin and all-cause and cardiovascular mortality: effect modification by adiponectin in end-stage kidney disease patients. Nephrol Dial Transplant 2013;28:iv181-187.

40 Machii N, Satoh H, Kudoh A, Watanabe T: Resistin Exacerbates Insulin Resistance under the Condition of Low Adiponectin in 3T3-L1 Adipocytes. J Diabetes Metab 2012;3:230.

41 Jamaluddin MS, Weakley SM, Yao Q, Chen C: Resistin: functional roles and therapeutic considerations for cardiovascular disease. Br J Pharmacol 2012;165:622-632.

42 Sabbisetti VS, Waikar SS, Antoine DJ, Smiles A, Wang C, Ravisankar A, Ito K, Sharma S, Ramadesikan S, Lee M, Briskin R, De Jager PL, Ngo TT, Radlinski M, Dear JW, Park KB, Betensky R, Krolewski AS, Bonventre JV: Blood kidney injury molecule-1 is a biomarker of acute and chronic kidney injury and predicts progression to ESRD in type I diabetes. J Am Soc Nephrol 2014;25:2177-2186.

43 Torregrosa I, Montoliu C, Urios A, Andrés-Costa MJ, Giménez-Garzó C, Juan I, Puchades MJ, Blasco ML, Carratalá A, Sanjuán R, Miguel A: Urinary KIM-1, NGAL and L-FABP for the diagnosis of AKI in patients with acute coronary syndrome or heart failure undergoing coronary angiography. Heart Vessels 2014;30:703711.

44 Yang L, Brooks CR, Xiao S, Sabbisetti V, Yeung MY, Hsiao LL, Ichimura T, Kuchroo V, Bonventre JV: KIM-1mediated phagocytosis reduces acute injury to the kidney. J Clin Invest 2015;125:1620-1636.

45 Gümüs A, Ozkaya S, Ozyurt S, Cinarka H, Kirbas A, Sahin U, Ece F: A novel biomarker in the diagnosis of parapneumonic effusion: neutrophil gelatinase-associated lipocalin. Multidiscip Respir Med 2014;9:49.

46 Smertka M, Wroblewska J, Suchojad A, Majcherczyk M, Jadamus-Niebroj D, Owsianka-Podlesny T, Brzozowska A, Maruniak-Chudek I: Serum and urinary NGAL in septic newborns. Biomed Res Int 2014;2014:717318.

47 Naudé PJ, Eisel UL, Comijs HC, Groenewold NA, De Deyn PP, Bosker FJ, Luiten PG, den Boer JA, Oude Voshaar RC: Neutrophil gelatinase-associated lipocalin: a novel inflammatory marker associated with latelife depression. J Psychosom Res 2013;75:444-450.

48 Liebetrau C, Dörr O, Baumgarten H, Gaede L, Szardien S, Blumenstein J, Rolf A, Möllmann H, Hamm C, Walther T, Nef H, Weber M: Neutrophil gelatinase-associated lipocalin (NGAL) for the early detection of cardiac surgery associated acute kidney injury. Scand J Clin Lab Invest 2013;73:392-399.

49 Hemdahl AL, Gabrielsen A, Zhu C, Eriksson P, Hedin U, Kastrup J, Thorén P, Hansson GK: Expression of neutrophil gelatinase-associated lipocalin in atherosclerosis and myocardial infarction. Arterioscler Thromb Vasc Biol 2006;26:136-142.

50 Kafkas N, Demponeras C, Zoubouloglou F, Spanou L, Babalis D, Makris K: Serum levels of gelatinase associated lipocalin as indicator of the inflammatory status in coronary artery disease. Int J Inflam 2012;2012:189797.

51 Ekart R, Bevc S, Hojs N, Knehtl M, Dvoršak B, Hojs R: Albuminuria is associated with subendocardial viability ratio in chronic kidney disease patients. Kidney Blood Press Res 2015;40:565-574. 